\title{
What Were the Driving and Charging Behaviors of High Mileage Accumulators?
}

Idaho National Laboratories

June 2015

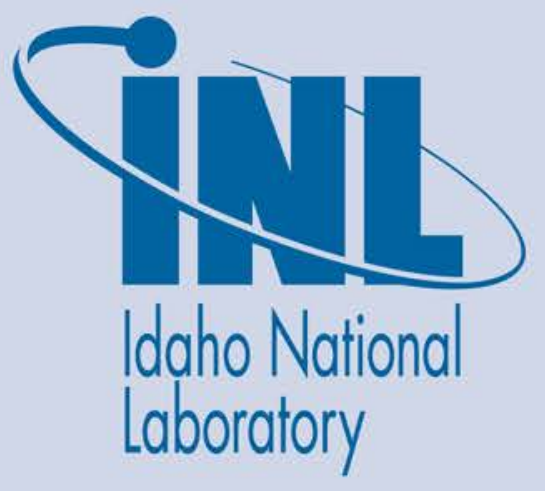

The INL is a U.S. Department of Energy National Laboratory operated by Battelle Energy Alliance 


\title{
What Were the Driving and Charging Behaviors of High Mileage Accumulators?
}

Idaho National Laboratory

June 2015

\section{Idaho National Laboratory \\ Idaho Falls, Idaho 83415}

http://www.inl.gov

\author{
Prepared for the \\ U.S. Department of Energy \\ Assistant Secretary for __, OR Office of \\ Under DOE Idaho Operations Office \\ Contract DE-AC07-05ID14517
}




\section{What Were the Driving and Charging Behaviors of High Mileage Accumulators?}

June 2015

\section{Key Conclusions}

- The 100 Nissan Leaf drivers who accumulated the most miles during their participation in The EV Project averaged over 55 miles per day driven. The average Leaf driver accumulated approximately 29 miles per day driven.

- The 100 Chevrolet Volt drivers who accumulated the most miles during their participation in The EV Project averaged over 68 miles per day. The average Volt driver accumulated approximately 39 miles per day driven.

- The Nissan Leaf driver with the most mileage during The EV Project accumulated over 95,000 miles and averaged 105 miles per day driven.

- The Chevrolet Volt driver with the most mileage over The EV Project participated for a shorter period of time when compared to the highest mileage Leaf driver, but accumulated nearly 65,000 miles and averaged 131 miles per day driven.

- The highest mileage accumulators used away-fromhome charging more frequently than the average EV Project participant.

\section{Introduction}

During The EV Project, data were collected from approximately 8,000 Nissan Leafs and Chevrolet Volts that accumulated over 124 million miles together while generating data.

There were significant differences in the technologies employed by the two primary vehicles in The EV Project (i.e., the Nissan Leaf and Chevrolet Volt). Because the Volt has an onboard, range-extending internal combustion engine (ICE) to recharge the battery while driving (i.e., extended-range mode), the vehicle could be driven much further between charges. The Leaf's range is limited by the battery capacity. However, unlike the Volt the Leaf can be "fast-charged," providing an opportunity to extend its daily travel distance.

Many plug-in electric vehicle (PEV) drivers in The EV Project accumulated miles at rates similar to what one would expect from an ICE vehicle. This paper examines some of the driving and charging characteristics of those
PEV drivers who accumulated the most miles on their vehicles.

\section{Data Analyzed}

In exchange for an alternating current (AC) Level 2 electric vehicle supply equipment unit installed in their home, participants in The EV Project allowed collection and analysis of data generated by the use of their PEV and the deployed Blink charging network.

Vehicle data were provided to the Idaho National Laboratory's (INL's) Advanced Vehicle Testing Activity by Nissan's CARWINGS ${ }^{\mathrm{TM}}$ vehicle telematics system and GM's OnStar ${ }^{\mathrm{TM}}$ for the Leaf and Volt, respectively. These vehicle data included the vehicle's odometer reading at each key event (on and off) and were used to determine miles travelled between key events. The key event was selected as the triggering event, because it is an indicator that the vehicle was ready to start a trip or had just completed a trip and may be ready to recharge the battery.

Time and date at the key events were also recorded and used to determine when the vehicle was driven. For more than 24 months of enrolling interested PEV drivers, PEV driver participation in The EV Project commenced at various times, resulting in varying durations of participation. Therefore, all reports regarding vehicle operation over time considered only the days the vehicle was driven and are identified as "per days driven." This metric provided a better means of comparing data as the project moved from the early adopters to the early majority.

\section{Observations}

\section{Mileage Accumulation}

The average American driver accumulates about $13,476^{1}$ miles per year, and the average PEV driver in The EV Project accumulated about 8,668 miles per year. However, the top 100 Leaf drivers accumulated an average of 19,048 miles per year and the top Volt drivers accumulated approximately 25,088 miles per year (Table 1).

Table 1. Daily and annual mileage accumulation per vehicle.

\begin{tabular}{|c|c|c|}
\hline \multicolumn{3}{|c|}{ PEV Mileage Accumulation in The EV Project } \\
\hline & $\begin{array}{l}\text { Average Miles } \\
\text { Per Day Driven }\end{array}$ & $\begin{array}{c}\text { Average } \\
\text { Annual Miles }\end{array}$ \\
\hline Leaf & 29 & \\
\hline Volt & 39 & \\
\hline Overall EV Project & & 8,668 \\
\hline All U.S. vehicles ${ }^{1}$ & & 13,476 \\
\hline Top 100 Leaf & 55 & 19,048 \\
\hline Top 100 Volt & 68 & 25,088 \\
\hline
\end{tabular}


The top Leaf drivers drove their vehicles almost twice as far per day driven as the average Leaf driver in The EV Project (55 vs. 29 miles per day driven). Meanwhile high mileage Volt drivers had a similar average daily accumulation of miles (68 vs. 39 miles per day driven).

The Volt's ability to extend range using its ICE led to the highest overall average miles per day driven at 131. However, only three Volts were driven more miles per day than the 2011 Nissan Leaf with the most miles accumulated and most miles per day driven at 105 miles. This Leaf has been the subject of many news reports (see Reference 2) and accumulated over 95,500 miles during The EV Project. This vehicle accumulated more than 100,000 miles overall.

\section{Battery Charging}

The highest mileage Leaf, like many of the high mileage PEVs, used a workplace charger to fully recharge the vehicle each day. This doubled the vehicle's ability to travel the maximum distance possible each day on battery-supplied power. As shown in Table 2, high mileage Leaf drivers, in particular, used away-fromhome charging for $34.1 \%$ of their charging compared to just 20 to $22 \%{ }^{\star}$ for all Leaf drivers participating in The EV Project.

Table 2. Percentage of charging done at home versus away-from-home.

\begin{tabular}{lcc}
\hline & $\begin{array}{c}\text { Charging Location } \\
\text { Home }\end{array}$ & Away \\
\hline Leaf & 78 to $80 \% \%^{*}$ & 20 to $22 \%{ }^{*}$ \\
Volt & 83 to $86 \% *$ & 14 to $17 \%{ }^{*}$ \\
Top 100 Leaf & $65.9 \%$ & $34.1 \%$ \\
Top 100 Volt & $79.3 \%$ & $20.7 \%$ \\
\hline * The range of home vs. away charging results from a 4 to $6 \%$ uncertainty in \\
\multicolumn{2}{l}{ location data generated by vehicle telematics. }
\end{tabular}

Volt drivers accumulating high miles did much of it using extended-range mode; therefore, they had only increased away-from-home charging to $20 \%$ compared to the 14 to $17 \%$ * for all Volt drivers participating in The EV Project. With a typical full-electric range of 30 to 35 miles, the high-mileage Volts driving an average of 68 miles per day accumulated nearly half of that mileage in extended-range mode.

Of course the Leaf does not have this range extending feature, but does have a larger capacity battery and the ability to fast charge. The Leaf's useable electric range can achieve the average daily miles the high-mileage drivers achieved without an additional charge. However, as the data in Table 2 indicate, the high-mileage Leaf drivers took advantage of away-from-home charging at nearly twice the rate of all Leaf drivers in The EV Project, utilizing workplace charging and direct current fast charging to accomplish their daily driving needs.

\section{Conclusions}

A number of participants in The EV Project were able to meet their higher-than-average personal transportation needs with a PEV. Volt drivers took advantage of their onboard, range-extending ICE to accumulate miles while still traveling half of their miles using only electricity. Leaf drivers took advantage of away-from-home charging with workplace, public accessible AC Level 2 and direct current fast chargers to meet their above-average travel needs. For both Volt and Leaf high mileage drivers in The EV Project, charging at home remained the dominant means of charging their PEVs.

\section{About The EV Project}

The EV Project was the largest PEV infrastructure demonstration project in the world, equally funded by the U.S. Department of Energy (DOE) through the American Recovery and Reinvestment Act and private sector partners. The EV Project deployed over 12,000 AC Level 2 charging stations for residential and commercial use and over 100 dual-port direct current fast chargers in 17 U.S. regions. Approximately 8,300 Nissan LEAFs ${ }^{\mathrm{TM}}$, Chevrolet Volts, and Smart ForTwo Electric Drive vehicles were enrolled in the project.

Project participants gave written consent for EV Project researchers to collect and analyze data from their vehicles and/or charging units. Data collected from the vehicles and charging infrastructure represented almost 125 million miles of driving and 4 million charging events. The data collection phase of The EV Project ran from January 1, 2011, through December 31, 2013. INL is responsible for analyzing the data and publishing summary reports, technical papers, and lessons learned on vehicle and charging unit use.

\section{Company Profile}

INL is one of DOE's 10 multi-program national laboratories. The laboratory performs work in each of DOE's strategic goal areas: energy, national security, science, and the environment. INL is the nation's leading center for nuclear energy research and development. Day-to-day management and operation of the laboratory is the responsibility of Battelle Energy Alliance.

For more information, visit avt.inl.gov/evproject.shtml and avt.inl.gov/chargepoint.shtml.

\section{References}

1. Federal Highway Administration home page, "Average Annual Miles Driven per Driver by Age Group" https://www.fhwa.dot.gov/ohim/onh00/bar8.htm. 
2. News articles published about the highest mileage Nissan Leaf that participated in The EV Project:

a. http://ipwhitenissanleaf.com/2012/08/05/highmileage-leafs-60000-miles-per-year/

b. http://www.greencarreports.com/news/1084588 update-on-high-mileage-2011-nissan-leafelectric-car

c. http://transportevolved.com/2013/12/16/stevemarshs-nissan-leaf-rolls-over-100000-miles-stillgoing-strong/. 